\section{OPEN ACCESS}

Edited by:

Marina Cerrone

New York University, United States

Reviewed by:

Sami Noujaim

USF Health, United States

William Louch

University of Oslo, Norway

${ }^{*}$ Correspondence:

Gary Tse

g.tse@surrey.ac.uk

Shuk Han Cheng

bhcheng@cityu.edu.hk

Wing Tak Wong

jack_wong@cuhk.edu.hk

Specialty section:

This article was submitted to

Cardiac Rhythmology,

a section of the journal

Frontiers in Cardiovascular Medicine

Received: 23 October 2020

Accepted: 13 January 2021

Published: 03 February 2021

Citation:

Tse G, Li KHC, Cheung CKY, Letsas KP, Bhardwaj A, Sawant AC,

Liu T, Yan G-X, Zhang $H$, Jeevaratnam K, Sayed N, Cheng SH and Wong WT (2021) Arrhythmogenic

Mechanisms in Hypokalaemia:

Insights From Pre-clinical Models.

Front. Cardiovasc. Med. 8:620539.

doi: 10.3389/fcrm.2021.620539

\title{
Arrhythmogenic Mechanisms in Hypokalaemia: Insights From Pre-clinical Models
}

\begin{abstract}
Gary Tse ${ }^{1,2 *}$, Ka Hou Christien $L^{3}{ }^{3}$, Chloe Kwong Yee Cheung ${ }^{4}$, Konstantinos P. Letsas ${ }^{5}$, Aishwarya Bhardwaj ${ }^{6}$, Abhishek C. Sawant ${ }^{6}$, Tong Liu ${ }^{1}$, Gan-Xin Yan ${ }^{7}$, Henggui Zhang ${ }^{8}$, Kamalan Jeevaratnam ${ }^{2}$, Nazish Sayed ${ }^{9,10,11}$, Shuk Han Cheng ${ }^{12,13,14 *}$ and Wing Tak Wong ${ }^{15 *}$

${ }^{1}$ Tianjin Key Laboratory of lonic-Molecular Function of Cardiovascular Disease, Department of Cardiology, Tianjin Institute of Cardiology, Second Hospital of Tianjin Medical University, Tianjin, China, ${ }^{2}$ Faculty of Health and Medical Sciences, University of Surrey, Guildford, United Kingdom, ${ }^{3}$ Faculty of Medicine, Newcastle University, Newcastle upon Tyne, United Kingdom, ${ }^{4}$ Li Ka Shing Faculty of Medicine, The University of Hong Kong, Hong Kong, China, ${ }^{5}$ Second Department of Cardiology, Laboratory of Cardiac Electrophysiology, Evangelismos General Hospital of Athens, Athens, Greece, ${ }^{6}$ Division of Cardiology, Department of Internal Medicine, State University of New York at Buffalo, Buffalo, NY, United States, ${ }^{7}$ Lankenau Institute for Medical Research and Lankenau Medical Center, Wynnewood, PA, United States, ${ }^{8}$ School of Physics and Astronomy, The University of Manchester, Manchester, United Kingdom, ${ }^{9}$ Stanford Cardiovascular Institute, Stanford University School of Medicine, Stanford, CA, United States, ${ }^{10}$ Institute for Stem Cell Biology and Regenerative Medicine, Stanford University School of Medicine, Stanford, CA, United States, ${ }^{11}$ Department of Medicine, Division of Cardiology, Stanford University School of Medicine, Stanford, CA, United States, ${ }^{12}$ Department of Biomedical Sciences, College of Veterinary Medicine and Life Science, City University of Hong Kong, Hong Kong, China, ${ }^{13}$ State Key Laboratory of Marine Pollution (SKLMP), City University of Hong Kong, Hong Kong, China, ${ }^{14}$ Department of Materials Science and Engineering, College of Science and Engineering, City University of Hong Kong, Hong Kong, China, ${ }^{15}$ School of Life Sciences, Chinese University of Hong Kong, Hong Kong, China
\end{abstract}

Potassium is the predominant intracellular cation, with its extracellular concentrations maintained between 3. 5 and $5 \mathrm{mM}$. Among the different potassium disorders, hypokalaemia is a common clinical condition that increases the risk of life-threatening ventricular arrhythmias. This review aims to consolidate pre-clinical findings on the electrophysiological mechanisms underlying hypokalaemia-induced arrhythmogenicity. Both triggers and substrates are required for the induction and maintenance of ventricular arrhythmias. Triggered activity can arise from either early afterdepolarizations (EADs) or delayed afterdepolarizations (DADs). Action potential duration (APD) prolongation can predispose to EADs, whereas intracellular $\mathrm{Ca}^{2+}$ overload can cause both EADs and DADs. Substrates on the other hand can either be static or dynamic. Static substrates include action potential triangulation, non-uniform APD prolongation, abnormal transmural repolarization gradients, reduced conduction velocity (CV), shortened effective refractory period (ERP), reduced excitation wavelength (CV $\times$ ERP) and increased critical intervals for re-excitation (APD-ERP). In contrast, dynamic substrates comprise increased amplitude of APD alternans, steeper APD restitution gradients, transient reversal of transmural repolarization gradients and impaired depolarization-repolarization coupling. The following review article will summarize the molecular mechanisms that generate these electrophysiological abnormalities and subsequent arrhythmogenesis.

Keywords: hypokalaemia, potassium, cardiac arrhythmia, conduction, repolarization 


\section{INTRODUCTION}

Hypokalaemia is the most common electrolyte abnormality found in hospitalized patients (1) and therefore represents an important cause of arrhythmias and associated mortality observed in clinical practice (2). It is commonly observed in patients with pre-existing heart conditions (3-5). Hypokalaemia manifests, in order of decreasing likelihood, due to (i) increased $\mathrm{K}^{+}$loss, (ii) transcellular $\mathrm{K}^{+}$shift into cells or (iii) reduced dietary $\mathrm{K}^{+}$intake. Increased loss of $\mathrm{K}^{+}$mostly occurs secondary to the use of diuretics or laxatives, or from diarrhea. Transcellular shift of $\mathrm{K}^{+}$into cells can be caused by medications, such as $\beta_{2}$ receptor agonists (6), hormonal abnormalities, or metabolic alkalosis (7). Decreased intake can develop in conditions such as anorexia, dementia or reduced appetite from malignancy.

The following features are observed on the electrocardiogram (ECG) during hypokalaemia: ventricular premature complexes (VPCs), prolonged QT interval, ST segment depression and the appearance of a $\mathrm{U}$ wave (8). Extracellular potassium concentration $\left(\left[\mathrm{K}^{+}\right]_{\mathrm{o}}\right)$ is negatively correlated with the development VPCs, with each unit decrease in $\left[\mathrm{K}^{+}\right]_{0}(\mathrm{mM})$ corresponding to a $28 \%$ increased risk of VPCs $(9,10)$. A potentially life-threatening form of ventricular tachycardia (VT) termed torsade de pointes (TdP) also manifests in hypokalemia (11), which in turn can degenerate into ventricular fibrillation (VF) and sudden cardiac death (12). Other cardiac rhythm abnormalities induced by hypokalaemia include atrial fibrillation (13) and atrial flutter (14).

Animal models, particularly guinea pigs (15-21) and mice (22-24), have provided much insight into the detailed mechanisms underlying hypokalaemia-induced arrhythmogenicity. In these models, arrhythmic activity has been observed during regular pacing (Figure 1A), programmed electrical stimulation that delivers S1S2 pacing (increasing premature S2 stimuli delivered following trains of regular S1 stimuli) (Figure 1B) and dynamic pacing (trains of regular S1 stimuli of decreasing basic cycle length) (Figure 1C). The review article aims to consolidate pre-clinical findings on the electrophysiological mechanisms underlying hypokalaemia-induced arrhythmogenicity.

\section{BASIC ELECTROPHYSIOLOGY: PRE-CLINICAL LESSONS FROM SMALL ANIMAL MODELS (MICE, RABBIT, AND GUINEA PIGS)}

Whether serving as a disease model for pharmaceutical purposes or toxicology, the use of animal models as fundamental building blocks has enabled rapid advances in biomedical knowledge (27). This is no different in cardiology, with mice, rabbit and guinea pigs considered to be the most frequently used animal models in experimental cardiac electrophysiology (28). However, despite similarities in cardiac ion channel distribution, salient differences in electrophysiological results are still observed between small animal species, especially within the context of hypokalaemia.

\section{Triggered Activity Can Arise From Afterdepolarizations}

At the cellular level, reduction in $\left[\mathrm{K}^{+}\right]_{\mathrm{o}}$ is expected to shorten the time course of repolarization by increasing the $\mathrm{K}^{+}$electrochemical gradient across the cell membrane. Recent experiments conducted in rabbit hearts showed that hypokalaemia activated the apamin-sensitive small-conductance calcium-activated potassium current ( $\mathrm{I}_{\mathrm{KAS}}$ ) to shorten action potential durations (APD), thereby preserving repolarization reserve (29). However, prolonged APDs are observed because of $\mathrm{I}_{\mathrm{Kr}}, \mathrm{I}_{\mathrm{K} 1}, \mathrm{I}_{\mathrm{Ks}}$, and $\mathrm{I}_{\mathrm{to}}$ inhibition (30-34). These repolarization abnormalities explain the electrocardiographic QT interval prolongation observed in clinical practice (35). In a similar hypokalaemic in vivo rabbit model, prolonged exposure to reduced $\left[\mathrm{K}^{+}\right]_{\mathrm{o}}$ was also found to be significantly correlated with decreased HERG channel density due to its internalization and subsequent degradation, which may play a major role in APD prolongation (36). Recently, reduced $\mathrm{Na}^{+} / \mathrm{K}^{+}$-ATPase currents have been identified as a contributory mechanism toward prolonged repolarization $(37,38)$. Normally, $\mathrm{Na}^{+}$and $\mathrm{Ca}^{2+}$ handling is closely coupled via the sodium-calcium exchanger (NCX), which uses the electrochemical gradients of both ions to exchange three $\mathrm{Na}^{+}$for $1 \mathrm{Ca}^{2+}$

A change in the morphology of the action potential, such as in triangulation reflected by an increase in the $\mathrm{APD}_{90}$ $\mathrm{APD}_{50}$ difference, is thought to increase the likelihood of inward current re-activation that in turn produces triggered activity over the terminal phases of action potential repolarization $(16,39)$. More severe reductions in $\left[\mathrm{K}^{+}\right]_{\mathrm{o}}$ can induce $\mathrm{Ca}^{2+}$ overload due to a combination of suppressed $\mathrm{Na}^{+}-\mathrm{K}^{+}$-ATPase activity, reversal of transport by the NCX, and reduced intracellular ATP concentrations $(40,41)$.

Afterdepolarizations refer to the oscillations in the membrane potential before the next action potential. They can occur early (early afterdepolarizations, EADs) or late (DADs, delayed afterdepolarizations). EADs can be subdivided into those that occur during phase 2 and phase 3. Hypokalaemia can generate both EAD types by distinct mechanisms. APD prolongation increases the susceptibility to phase 2 EADs because of a wider window over which the L-type $\mathrm{Ca}^{2+}$ channels can be reactivated $(42,43) . \mathrm{Ca}^{2+}$ overload can promote EADs during phase 3 of the action potential (and during phase 2 in some species), thereby activating the NCX to mediate $\mathrm{Na}^{+}$entry $(44,45)$. Recent experiments in rabbit hearts showed that when combined with increased beta-adrenergic drive, $\mathrm{I}_{\text {KATP }}$ can be activated, leading to heterogeneous APD shortening and the subsequent generation of late phase 3 EADs in the presence of enhanced $\mathrm{Ca}^{2+}$. Intracellular $\mathrm{Ca}^{2+}$ accumulation can promote DADs. Isolated, perfused ventricular muscle in guinea pig (46) and rabbit (47) hearts have exhibited DADs in severe, experimental hypokalaemia.

Both EADs and DADs can lead to triggered activity (Figure 1A), thereby initiating arrhythmic activity and producing a sustained tachycardia upon encountering favorable reentrant substrates $(48,49)$. Such substrates can be revealed by programmed electrical stimulation (PES) (Figure 1B) or 


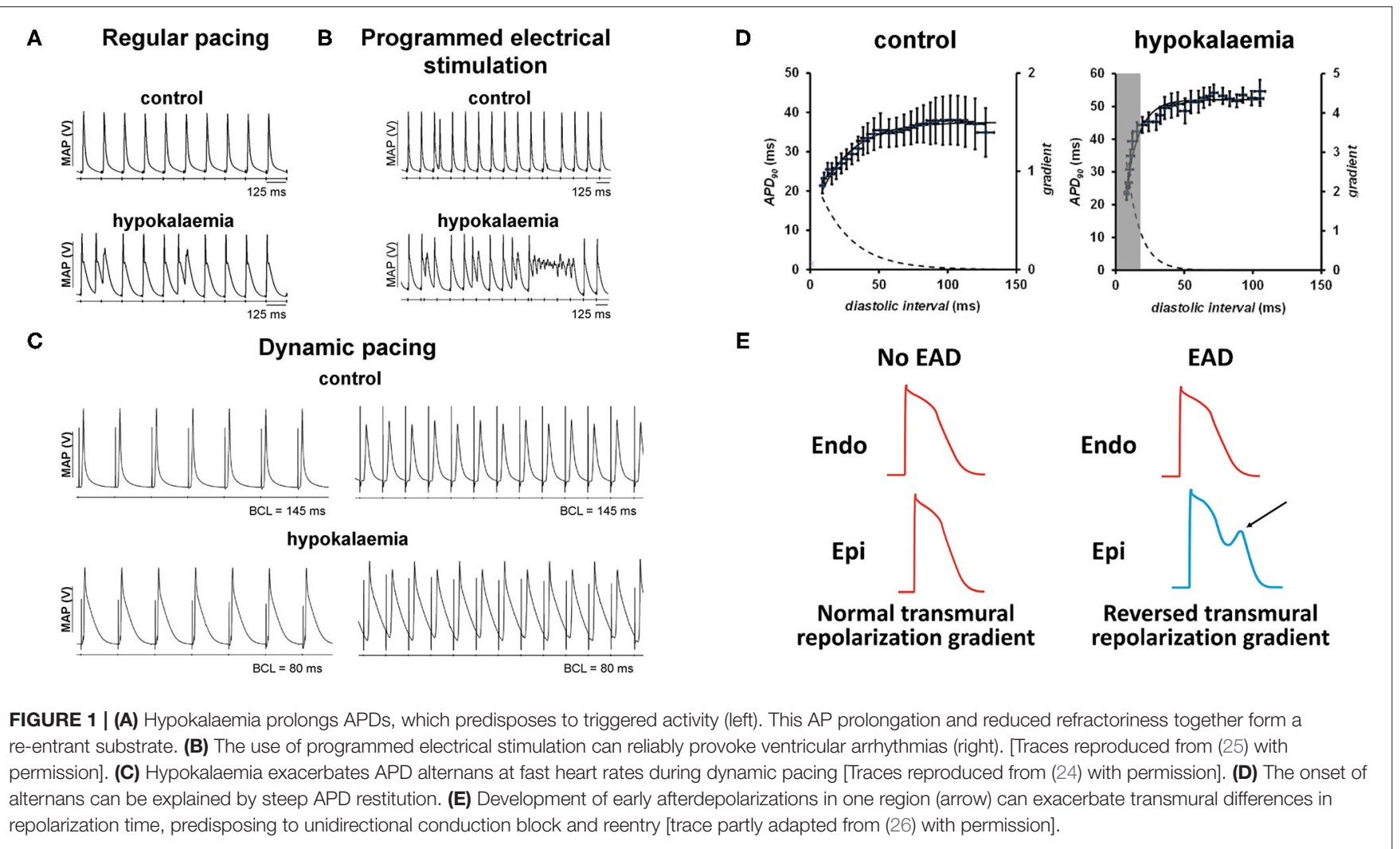

dynamic pacing (Figure 1C). Dynamic pacing can unmask APD alternans at short basic cycle lengths (BCLs), which can be explained by steep restitution in hypokalaemia compared to control conditions (Figure 1D). EADs, DADs or triggered activity can themselves increase the spatial heterogeneity in repolarization as well as areas of slowed conduction. In other words, triggers of arrhythmias may themselves create the substrates for re-entry (50), as demonstrated recently in modeling studies (51). Normally, endocardial APD is longer than epicardial APD resulting in a normal repolarization gradient (Figure 1E, left). When an EAD (arrow) develops, epicardial APD will be longer than endocardial APD, causing a reversal in the transmural repolarization gradient (Figure 1E, right) that is potentially arrhythmogenic $(16,17,20)$.

\section{Reentry Is Due to Static and Dynamic Abnormalities in Repolarization, Refractoriness and Conduction}

Numerous static and dynamic re-entrant substrates contribute to increased arrhythmogenicity in hypokalaemia (52).

\section{Repolarization: Steep Spatial Gradients}

The most important experimental finding consistently observed across the different species during hypokalaemia is non-uniform prolongation of repolarization, be it when comparing the left (LV) and right ventricle (RV), epicardium and endocardium, or apex and cardiac base $(16,53)$. Spatial differences in repolarization are thought to increase the risk of unidirectional conduction block, a prerequisite for circus-type or spiral wave reentry (54). Such spatial variations in repolarization may be present during regular pacing and further exacerbated following triggered activity, thereby enhancing arrhythmic risk. In guinea pig hearts, greater $\mathrm{APD}_{90}$ prolongations were seen in the RV epicardium relative to the LV epicardium $(16,53)$. These APD differences were attributed to differing expression patterns and levels of ion channels, in particular higher density of $\mathrm{I}_{\mathrm{K} 1}$ channels in the LV compared to in the RV $(55,56)$. The consequence of $\mathrm{RV} \mathrm{APD}_{90}$ prolongation during hypokalaemia is an increased RV-LV transepicardial $\mathrm{APD}_{90}$ difference compared to control during both regular and S1S2 pacing (16), which partly underlies the capacity of VPCs to induce sustained VT $(57,58)$.

In addition to transepicardial repolarization gradients, transmural gradients may contribute to arrhythmogenesis in hypokalaemia. Experimental data obtained from mouse hearts have been conflicting, as pointed out previously (16). LV epicardial and LV endocardial $\mathrm{APD}_{90}$ difference was found to be either unaltered (59) or reduced $(23,43)$. In guinea pig hearts, there was no demonstratable $\mathrm{APD}_{90}$ difference between the epicardium endocardium under either normokalaemic or hypokalaemic conditions. Moreover, transient alterations in transmural repolarization gradients have been explored in mouse hearts (60). It was shown that the S2 stimulus proportionally decreased epicardial and endocardial $\mathrm{APD}_{90}$. After the following S3 stimulus, endocardial $\mathrm{APD}_{90}$ decreased 
more sharply than did epicardial $\mathrm{APD}_{90}$, albeit the former recovered after $\mathrm{S} 4$ stimulation.

\section{Repolarization: Steep APD Restitution Gradients and APD Alternans}

The relationships between APD, the diastolic interval (DI) and basic cycle length are detailed in Figure 2A. The relationship $\mathrm{BCL}=\mathrm{APD}+\mathrm{DI}$ can be shown graphically as a straight line with a gradient of -1 . The original descriptions of alternans were based on a graphical method that related them to restitution of APD (61). APD restitution is the APD abbreviation that occurs when heart rate is increased and reflects an adaptive response to maintain a period of diastole, allowing blood to refill in the cardiac chambers. In a normal APD restitution curve (Figure 2B), APD is plotted against the previous DI. This relationship can be represented by the equation $\mathrm{APD}_{n+1}=\mathrm{f}$ $\left(\mathrm{DI}_{n}\right)$, where $\mathrm{f}$ is the function relating the new APD to its previous DI. When DI shortens, APD also shortens to accommodate. The region for long DIs is almost flat, whereas the region at short DIs is steep.

The restitution gradient reflects the recovery of the different ion channels that are activated during action potential generation. $\mathrm{Na}^{+}$channels show the fastest inactivation kinetics and recover quickly, and their effects on restitution are observed mostly at the shortest DIs. The $\mathrm{Ca}^{2+}$ channels recover at a slower rate compared to $\mathrm{Na}^{+}$channels, and their effects are observed at longer DIs. Because these channels mediate much of the transmembrane currents during the action potential plateau, they affect APD restitution greatly. $\mathrm{K}^{+}$channels have the slowest recovery rates compared to $\mathrm{Na}^{+}$and $\mathrm{Ca}^{2+}$ channels and their effects are therefore mostly observed at long DIs. An important property of $\mathrm{K}^{+}$channels is their reverse use dependence, in which increasing use leads to a lower level of channel blockade (62). As hypokalaemia inhibits $\mathrm{K}^{+}$channels, its effects are most prominent at long DIs, which may occur during a compensatory pause following an ectopic beat, and bradycardia. In hypokalaemia, due to the APD prolongation, the DIs can engage the steeper portion of the restitution curve even when heart rate is normal.

Cobweb plots can be used to illustrate the stability of beatto-beat alternations in APD (Figures 2C,D). In the original formulation, it is assumed that the DI depends on the preceding $\mathrm{APD}$. The line of the equation, $\mathrm{DI}=\mathrm{BCL}-\mathrm{APD}$, represents the feedback mechanism, where DI is inversely related to APD. If APD is longer, then the next DI is shorter. The APD equilibrium point at each BCL is located at the intersection between this line and the restitution curve. A sudden increase in heart rate, as reflected by a decrease in BCL, leads to shortening of APD. Under normal conditions, the restitution gradient is $<1$. With a perturbation leading to a small decrease in DI, the next APD decreases. For the next beat, the DI increases, but to a value smaller than the original DI. Each iteration leads to a smaller beat-to-beat difference in APD and DI, until eventually a stable point is reached (Figure 2C). In hypokalemia, the restitution gradient is steeper at the same range of DIs (63). Each iteration leads to a successive increase in the beat-to-beat variation in APD, leading to 2:1 block (Figure 2D). A special case occurs if the restitution gradient is exactly 1 , in this case, alternans do not converge or diverge, and become stable.

The appearance of APD alternans has been associated with steeper APD restitution. However, it should be stressed that restitution is not the only factor that determines the presence or absence of alternans. Thus, other factors such as electronic and memory effects can suppress APD alternans even when the APD restitution gradient is $>1$ (64). Moreover, normally APD is closely coupled to the effective refractory period (ERP). Yet, APD is prolonged but ERP is shortened in hypokalaemia. Thus, APD restitution may not accurately predict the onset of alternans in this situation and VERP restitution may be a better indicator (18). Conversely, APD alternans can occur when the APD restitution gradient is $<1$ when restitution-dependent mechanisms are present (65). However, these effects have not been studied in detail for hypokalaemia. Finally, the relationships between repolarization dynamics, membrane excitability and cardiac memory are complex and warrants further study (66-71).

Electrical restitution can generally be assessed by two stimulation protocols: dynamic pacing and S1S2 pacing measure the steady-state response and the intermediate response, respectively, of the myocardium to a change in the basic cycle length (BCL). S1S2 pacing has the advantage of safety because pacing at a high heart rate is not required $(19,72$, 73), albeit this method cannot assess beat-to-beat variations, that is, alternans, in action potential properties. In contrast, dynamic pacing can induce myocardial ischaemia $(74,75)$, but can be used experimentally to quantify alternans. In mice, greater amplitudes of epicardial $\mathrm{APD}_{90}$ alternans associated with increased maximum $\mathrm{APD}_{90}$ restitution gradients were observed during dynamic pacing in hypokalaemia compared to in normokalaemia (Figure 1D) (63). Endocardial $\mathrm{APD}_{90}$, maximum $\mathrm{APD}_{90}$ restitution gradients and $\mathrm{DI}_{\text {crit }}$ were not altered $(23,63)$. However, guinea pig hearts showed significant differences, such as increased endocardial $\mathrm{APD}_{90}$ restitution gradients (18) and $\mathrm{APD}_{90}$ alternans despite shallower $\mathrm{APD}_{90}$ restitution gradients (18). Recent experiments in mouse hearts have further separated the roles of abnormal electrical restitution from other electrophysiological substrates in hypokalaemia (24). Moreover, these data provide the proof-of-concept that restitution can be assessed by both dynamic and S1S2 pacing procedures with largely agreeable restitution parameters.

\section{Reduced Refractoriness and Steep ERP Restitution}

The refractoriness of the myocardium, which can be measured experimentally as the effective refractory period (ERP), is an important determinant of the likelihood of reentry for the following reasons. Firstly, a decrease in the excitation wavelength, $\lambda$ [conduction velocity $(\mathrm{CV}) \times \mathrm{ERP}$ ] increases the number of reentry circuits available within the myocardium (Figure 2E) (76). Secondly, an increase in the critical interval given by APD-ERP would prolong the time window during which reexcitation can take place, potentially by reactivation of inward $\mathrm{Na}^{+}$and $\mathrm{Ca}^{2+}$ currents (59). Furthermore, reduced ERP can decrease the core size around which a spiral wave can meander (77). Shortening of ERP is observed during hypokalaemia despite concomitant APD prolongation. Studies in mouse and 


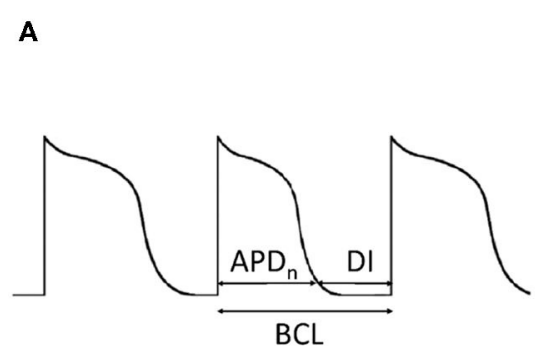

C

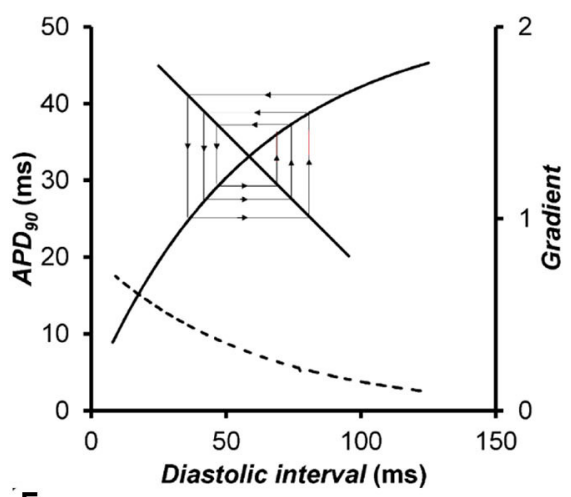

E

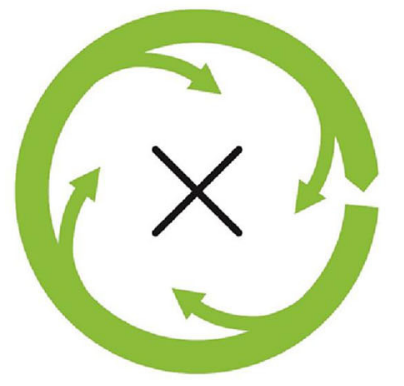

$\mathbf{F}$

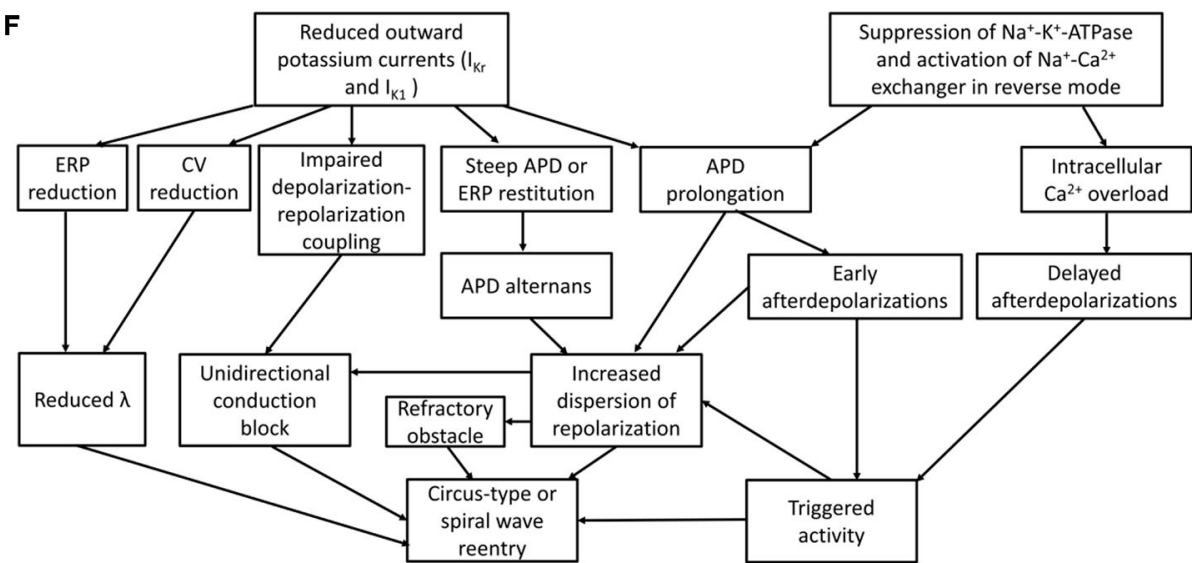

B

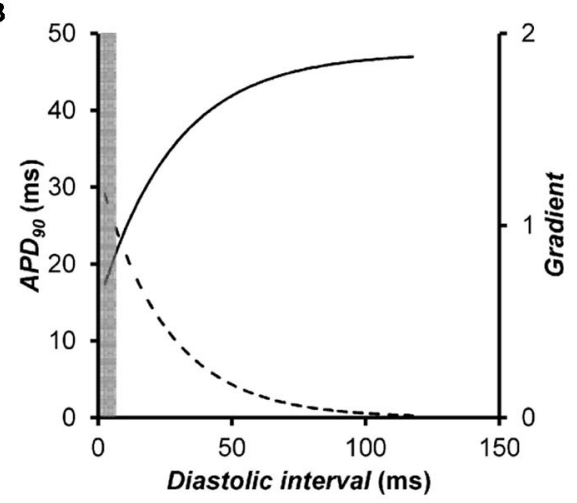

D

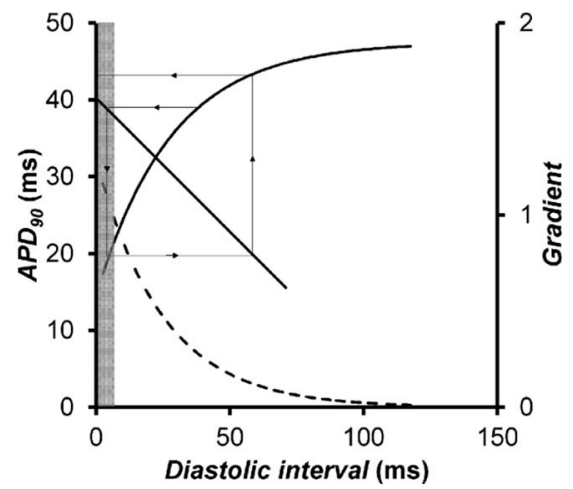

\section{$\lambda=C V \times E R P$}

\section{If $\lambda<$ length of the circuit $\rightarrow$ higher risk of reentry}

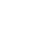


FIGURE 2 | line. The values of Dls at which such gradients are $>1$ are represented by the gray box. (C) APD restitution curve plotting APD against the previous DI (solid line) along with their gradients (broken line). The values of Dls with gradients $>1$ are represented by the gray box. The cobweb plot shows that when the APD restitution gradient is $<1$, a stable equilibrium point is produced on successive beats. (D) APD restitution curve plotting APD against the previous DI (solid line) along with their gradients (broken line). The values of Dls with gradients $>1$ are represented by the gray box. The cobweb plot shows that when the APD restitution gradient is $>1$, an unstable equilibrium point is produced on successive beats, eventually leading to conduction block. Reproduced from (52) with permission. (E) Circus-type reentry depends on the wavelength of excitation, given by the product of conduction velocity and effective refractory period [Figures adapted from (26) with

permission]. (F) Summary of different electrophysiological mechanisms that are responsible for triggered activity and reentry in hypokalaemia.

guinea pig hearts showed that LV epicardial and endocardial ERPs were decreased by similar extents $(16,23)$. Though debatable, this ERP shortening was found to be associated with excessive hyperpolarization of the resting membrane potential in ventricular cardiomyocytes. This subsequently results in increased activation of fast $\mathrm{Na}^{+}$channels, leading to a more pronounced action potential amplitude and an increased upstroke velocity during the depolarization phase (17). Under normokalaemic conditions, the critical opening for LV reexcitation is narrow, rendering the induction of re-excitation highly unlikely. Therefore, it is no surprise that prolongation of the critical interval from reduced $\left[\mathrm{K}^{+}\right]_{\mathrm{o}}$ is associated with an increased likelihood of sustained triggered activity over terminal repolarization (16). Recent experiments in guinea pigs demonstrate a contributory role of steep ERP restitution in predisposing the tissues to the generation of alternans and reentry (18).

\section{Conduction Slowing}

Conduction velocity $(\mathrm{CV})$ is governed by $\mathrm{Na}^{+}$channels and gap junctions (78). Hypokalaemia is known to decrease CV in the atria, atrioventricular node, Purkinje fibers and the ventricles (16, 79). The underlying mechanism is thought to involve depressed membrane excitability from membrane depolarization, increased threshold potential for $\mathrm{Na}^{+}$channel activation and increased membrane resistance $(80,81)$. Enhanced stimulation threshold, decreased LV to RV transepicardial and LV epicardial to endocardial transmural CVs were all observed in guinea pigs during both regular and S1S2 pacing (16). In contrast, local epicardial and endocardial $\mathrm{CV}$ as well as transmural CV were not altered in hypokalaemic mouse hearts (59).

\section{Impaired Activation-Repolarization Coupling and Other Arrhythmogenic Factors}

Activation-repolarization coupling is an intrinsic property of the myocardium, allowing local APD values to be adjusted to conduction slowing at different myocardial sites along the path of the propagating action potential (21). This effect has been attributed to modulation of APD in neighboring cardiomyocytes by gap junction conduction, which would reduce regional differences in APD (82). Normally, the APD difference between the RV and LV is minimized by delayed LV activation, an effect that is impaired by hypokalaemia (21).

It is worth noting that arrhythmogenicity is stimulation site-dependent. Experiments in guinea pig hearts showed that ventricular arrhythmias were readily inducible upon LV stimulation, whereas RV stimulation failed to induce arrhythmic events (15). This observation can be attributed to interventricular differences in ion channel expression. Thus, larger $I_{\mathrm{K} 1}$ is found in the LV compared to in the RV, which would be expected to shorten APDs and therefore ERPs to greater extents in the LV. A steep repolarization gradient between the epicardium and endocardium, and between the LV and RV, can lead to a block of an action potential, favoring reentry. All of the above electrophysiological mechanisms underlying arrhythmogenesis in hypokalaemia are summarized in Figure 2F.

\section{BASIC ELECTROPHYSIOLOGY: LARGER ANIMAL MODELS-CANINE, CAT AND SHEEP}

It is important to note the fundamental relationship and differences between body weight and various cardiovascular parameters across all types of laboratory animals. An equation encapsulating this concept was coined in 1979 as heart weight $\left(\mathrm{HW}(\mathrm{g})=6.0 \times \mathrm{BM}^{0.98}\right)$ and $\mathrm{P}-\mathrm{R}$ interval $(\mathrm{PR}(\mathrm{ms})=53 \times$ $\mathrm{BM}^{0.24}$ ) where $\mathrm{BM}$ is body mass in $\mathrm{kg}$ (83). Such differences are reinforced in electrophysiology, where small rodents are found with significantly shorter APD than humans due to lack of a prominent plateau phase found in cardiomyocytes (84-86). Therefore, the rabbit myocardium presents a more representative model of the human heart. Despite this similarity, important inter-species variations remain especially when $\mathrm{K}^{+}$handling is examined. Cardiac $\mathrm{K}^{+}$channel expression is significantly different between rabbits, guinea pigs and humans, accounting for the increased susceptibility to ventricular fibrillation in rabbit hearts, as well as the reduced transient outward current and large slow component of the delayed rectifier current in guinea pigs (87).

Furthermore, it is imperative to consider the potential usage of other relevant cardiovascular animal models. Similar to rabbit models, canine heart models show similar cardiac ion channel distribution with human hearts, making them suitable for the study of ion-channel-related mechanisms (e.g., repolarization and depolarization mechanics) and arrhythmic drug effects. Moreover, canine heart models have a much more comparable APD, sino-atrial node activity, Purkinje fiber distribution and activation sequence to humans (88-90). In contrast, goat and horse models have also shown to be suitable for the study of atrial fibrillation given the ease of obtaining ECG recordings (28, 91, 92). Regardless, mainly canine, cat and sheep models have been used to investigate electrophysiological changes in hypokalaemia.

Canine and sheep models were similar to smaller animal models with regards to an observed reduction in conduction 
velocity during hypokalaemia across the cardiac conduction system (atria, atrioventricular node, Purkinje fibers and the ventricles) $(93,94)$. The underlying mechanism was thought to involve depressed membrane excitability from membrane depolarization, increased threshold potential for $\mathrm{Na}^{+}$channel activation and increased membrane resistance (80). However, further experiments have shown differing effects of hypokalaemia on epicardial vs. endocardial APD parameters (95) as well as regional differences in repolarization in canine hearts, due to greater $I_{K s}$ and $I_{\text {to }}$ in RV compared to in the LV (96, 97). This shows that both the interlayer restitution gradient and transepicardial APD difference constitute viable pathways for arrhythmogenesis.

\section{DIFFERENTIAL EFFECTS OF HYPOKALAEMIA ON DISTINCT CELL TYPES}

Arrhythmogenic mechanisms in atrial and ventricular cell types can differ. For example, EADs in ventricular cardiomyocytes and tubulated atrial cardiomyocytes are attributed to $\mathrm{Ca}^{2+}$ overload (98). However, phase 3 EADs in untubulated atrial cardiomyocytes are instead linked to the reactivation of non-equilibrium $\mathrm{Na}^{+}$current and are driven by membrane hyperpolarization and short action potential configurations (98). Furthermore, hypokalaemia induces $\mathrm{Ca}^{2+}$ overload in ventricular cardiomyocytes by reduced pumping rate of the $\mathrm{Na}^{+}-\mathrm{K}^{+}$-ATPase leading to subsequent $\mathrm{Na}^{+}$accumulation (37). Moreover, structurally and functionally different small conductance $\mathrm{Ca}^{2+}$-activated $\mathrm{K}^{+}$-channel (KCa2) inhibitors, ICA, AP14145, and AP30663, exerted anti-arrhythmic effects in hypokalaemic guinea pig hearts (99). In contrast, KCa2 blockade was found to be pro-arrhythmic in rabbit hearts (29), the reasons for which may be attributed to species differences or variations in the pharmacological agents used (ICA, AP14145, and AP30663 vs. apamin) (99). Both AP14145 and AP30663 can inhibit the late $\mathrm{Na}^{+}$current at higher concentrations (100). Indeed, the increase in intracellular $\mathrm{Ca}^{2+}$ can activate $\mathrm{Ca}^{2+}$-calmodulin-dependent kinase to increase the activity of the late $\mathrm{Na}^{+}$channel (38). Hypokalaemia can also cause conduction abnormalities in the cardiac conduction system, although not to the same extent as hyperkalaemia. Thus, it can cause slowed conduction of action potentials through the atrioventricular node in canine $(94,101)$ and rabbit hearts (81), an abnormality that has also been reported in humans (102).

\section{BRIDGING OVER FROM BASIC TO CLINICAL ELECTROPHYSIOLOGY}

Human cardiac models tend to have differences in repolarization reserve when compared to animal models, depending on cardiac miRNA levels for ion channel subunit production (103). Utilizing human induced pluripotent stem cell-derived engineered heart tissue can overcome this human-to-animal model gap to better simulate physiological outcomes in humans (104). While there is a limited understanding specifically on the implications of steep AP restitution gradients within the context of human hypokalaemia, the heterogeneity of APD restitution slopes have been proposed as a substrate for arrhythmogenesis in a wholeheart modeling study (105). This phenomenon was subsequently confirmed by the introduction of the Regional Restitution Instability Index (R2I2) by Nicholson and colleagues $(106,107)$.

\section{HYPOKALAEMIA IN THE CLINICAL CONTEXT}

The importance of understanding the underlying mechanisms during hypokalaemia resides in its relationship with the development cardiac arrhythmias in various clinical conditions. Hypokalaemia is associated with increased risks of atrial fibrillation amongst hospitalized patients (108). Moreover, hypokalaemia is common in patients presenting with VT/VF, and those with severe hypokalaemia have found to be associated with preceding gastrointestinal illness, higher doses of diuretics (109), use of drugs such as anti-depressants (110), as well as post-operative settings (111). In patients with implantable cardioverter-defibrillators (ICDs), hypokalaemia but not hyperkalaemia has been linked with increasing risk of recurrent ventricular tachyarrhythmias and appropriate ICD therapies (112). However, it should be stressed that the relationship between hypokalaemia and adverse outcomes is complex, in that it may or may not be an independent predictor of mortality (113) and that its correction may not lead to better outcomes in hospitalized patients (114). Moreover, altered repolarization correlates with prolonged QTc and $\mathrm{T}_{\text {peak }}-\mathrm{T}_{\text {end }}$ intervals in pre-clinical experimental studies (99). Both ECG indices have been reported to provide predictive value for arrhythmic risk stratification in the clinical context of acquired long QT syndrome for humans (115). Indeed, in a Chinese cohort of patients with acquired long QT syndrome, random survival forest analysis identified hypokalaemia as the second most important variable after cancer for predicting all-cause mortality (116).

In heart failure, the use of diuretics and activation of the reninangiotensin system are the predominant causes of hypokalaemia (117). Ventricular arrhythmias, particularly non-sustained VT, are common $(118,119)$, involving both triggered and re-entrant arrhythmias have been described (120-122). A recent metaanalysis suggested a strong inverse association between serum $\mathrm{K}^{+}$ channel concentration and ventricular arrhythmias in patients with myocardial infarction (123). In a large animal model of chronic post-myocardial infarction fibrosis, hypokalaemia revealed vulnerable electrophysiological substrates, which highlighted the importance of conduction slowing over repolarization instability in its arrhythmogenesis (124). Thus, clinical decision-making should take into consideration hypokalaemia as a common side effect of diuretics in patients with prior myocardial infarction $(125,126)$. In emergency settings, serum $\mathrm{K}^{+}$concentrations on admission alone or together with the co-existing Thrombolysis in Myocardial Infarction (TIMI) risk score was shown to predict more accurately short- and long-term risk of malignant ventricular 
arrhythmias respectively $(127,128)$. Moreover, hypokalaemia is not only a risk factor for VT/VF in the acute phase of ST-segment-elevation myocardial infarction (STEMI), but is also associated with VF before primary percutaneous coronary intervention (129). Finally, hypokalaemia exerts pro-arrhythmic effects in congenital long QT syndrome, such as in the context of salt-wasting nephropathy (130). In otherwise silent mutational carriers, it can reveal a long QT phenotype $(131,132)$. In such patients, $\mathrm{K}^{+}$supplement can protect congenital LQTS patients or silent carriers against the development of VT/VF $(133,134)$.

\section{CONCLUSION}

This article reviewed the electrophysiological mechanisms of triggered and re-entrant arrhythmogenesis in hypokalaemia, in which the data were largely derived from pre-clinical animal models. Prolonged repolarization can cause EADs, and $\mathrm{Ca}^{2+}$ handling can lead to the development of both EADS and DADs, leading to triggered activity. Reduced conduction velocity,

\section{REFERENCES}

1. Rastegar A, Soleimani M. Hypokalaemia and hyperkalaemia. Postgrad Med J. (2001) 77:759-64. doi: 10.1136/pgmj.77.914.759

2. Soar J, Deakin CD, Nolan JP, Abbas G, Alfonzo A, Handley AJ, et al. European resuscitation council guidelines for resuscitation 2005. Section 7. Cardiac arrest in special circumstances. Resuscitation. (2005) 67:S135-70. doi: 10.1016/j.resuscitation.2005.10.004

3. Solomon RJ, Cole AG. Importance of potassium in patients with acute myocardial infarction. Acta Med Scand Suppl. (1981) 647:87-93. doi: 10.1111/j.0954-6820.1981.tb02643.x

4. Johansson BW, Dziamski R. Malignant arrhythmias in acute myocardial infarction. Relationship to serum potassium and effect of selective and non-selective beta-blockade. Drugs. (1984) 28:77-85. doi: 10.2165/00003495-198400281-00008

5. Clausen TG, Brocks K, Ibsen H. Hypokalemia and ventricular arrhythmias in acute myocardial infarction. Acta Med Scand. (1988) 224:531-7. doi: 10.1111/j.0954-6820.1988.tb19623.x

6. Brown MJ. Hypokalemia from beta 2-receptor stimulation by circulating epinephrine. Am J Cardiol. (1985) 56:3D-9D. doi: 10.1016/0002-9149(85)91107-5

7. Adrogué HJ, Madias NE. Changes in plasma potassium concentration during acute acid-base disturbances. Am J Med. (1981) 71:456-67. doi: 10.1016/0002-9343(81)90182-0

8. Helfant RH. Hypokalemia and arrhythmias. Am J Med. (1986) 80:13-22. doi: 10.1016/0002-9343(86)90336-0

9. Cohen JD, Neaton JD, Prineas RJ, Daniels KA. Diuretics, serum potassium and ventricular arrhythmias in the multiple risk factor intervention trial. $A m$ J Cardiol. (1987) 60:548-54. doi: 10.1016/0002-9149(87)90303-1

10. Dargie HJ, Cleland JG, Leckie BJ, Inglis CG, East BW, Ford I. Relation of arrhythmias and electrolyte abnormalities to survival in patients with severe chronic heart failure. Circulation. (1987) 75:IV98-107.

11. Dessertenne F. La tachycardie ventriculaire a deux foyers opposes variable. Arch Mal Coeur. (1966) 56:263-72.

12. Gettes LS, Surawicz B, Shiue JC. Effect of high K, and low K quinindine on QRS duration and ventricular action potential. Am J Physiol. (1962) 203:1135-40. doi: 10.1152/ajplegacy.1962.203.6.1135

13. Krijthe BP, Heeringa J, Kors JA, Hofman A, Franco OH, Witteman JCM, et al. Serum potassium levels and the risk of atrial fibrillation: the rotterdam study. Int J Cardiol. (2013) 168:5411-5. doi: 10.1016/j.ijcard.2013.08.048

14. Varriale P, Kwa RP, Parikh N. Atrial flutter secondary to hypokalemia. Pacing Clin Electrophysiol. (1983) 6:8-12. doi: 10.1111/j.1540-8159.1983.tb06574.x prolonged repolarization, increased dispersion of repolarization, reduced refractoriness, steep APD restitution gradients, transient reversal of transmural repolarization gradients and impaired depolarization-repolarization coupling, all collectively contribute to reentrant arrhythmogenesis.

\section{AUTHOR CONTRIBUTIONS}

GT and WW: drafting of manuscript, revision of manuscript, preparation of figures, and data interpretation. All other authors: drafting of manuscript, revision of manuscript, and data interpretation.

\section{FUNDING}

This study was supported by the Hong Kong Research Grants Council Grant ECS (24163117), GRF (14101119), National Natural Science Foundation of China (81970423) and CUHK direct grant to WW.

15. Osadchii OE, Bentzen BH, Olesen SP. Chamber-specific effects of hypokalaemia on ventricular arrhythmogenicity in isolated, perfused guinea-pig heart. Exp Physiol. (2009) 94:434-46. doi: 10.1113/expphysiol.2008.045567

16. Osadchii OE, Olesen SP. Electrophysiological determinants of hypokalaemia-induced arrhythmogenicity in the guinea-pig heart. Acta Physiol. (2009) 197:273-87. doi: 10.1111/j.1748-1716.2009.02028.x

17. Osadchii OE. Mechanisms of hypokalemia-induced ventricular arrhythmogenicity. Fundam Clin Pharmacol. (2010) 24:547-59. doi: $10.1111 / \mathrm{j} .1472-8206.2010 .00835 . x$

18. Osadchii OE, Larsen AP, Olesen SP. Predictive value of electrical restitution in hypokalemia-induced ventricular arrhythmogenicity. Am J Physiol Heart Circ Physiol. (2010) 298:H210-220. doi: 10.1152/ajpheart.00695.2009

19. Osadchii OE. Effects of ventricular pacing protocol on electrical restitution assessments in guinea-pig heart. Exp Physiol. (2012) 97:807-21. doi: 10.1113/expphysiol.2012.065219

20. Osadchii OE. Impact of hypokalemia on electromechanical window, excitation wavelength and repolarization gradients in guinea-pig and rabbit hearts. PLoS ONE. (2014) 9:e105599. doi: 10.1371/journal.pone.0105599

21. Osadchii OE. Impaired epicardial activation-repolarization coupling contributes to the proarrhythmic effects of hypokalaemia and dofetilide in guinea pig ventricles. Acta Physiol. (2014) 211:48-60. doi: 10.1111/apha.12259

22. Choy L, Yeo JM, Tse V, Chan SP, Tse G. Cardiac disease and arrhythmogenesis: mechanistic insights from mouse models. Int J Cardiol Heart Vasc. (2016) 12:1-10. doi: 10.1016/j.ijcha.2016. 05.005

23. Tse G, Tse V, Yeo JM, Sun B. Atrial anti-arrhythmic effects of heptanol in Langendorff-perfused mouse hearts. PLoS ONE. (2016) 11:e0148858. doi: 10.1371/journal.pone.0148858

24. Tse G, Wong ST, Tse V, Yeo JM. Restitution analysis of alternans using dynamic pacing and its comparison with S1S2 restitution in heptanoltreated, hypokalaemic Langendorff-perfused mouse hearts. Biomed Rep. (2016) 4:673-80. doi: 10.3892/br.2016.659

25. Tse G, Tse V, Yeo JM. Ventricular anti-arrhythmic effects of heptanol in hypokalaemic, Langendorff-perfused mouse hearts. Biomedical Reports. (2016) 4:313-24. doi: 10.3892/br.2016.577

26. Tse G, Lai ET, Lee AP, Yan BP, Wong SH. Electrophysiological mechanisms of gastrointestinal arrhythmogenesis: lessons from the heart. Front Physiol. (2016) 7:230. doi: 10.3389/fphys.2016.00230

27. Shanks N, Greek R, Greek J. Are animal models predictive for humans? Philos Ethics Humanit Med. (2009) 4:2. doi: 10.1186/1747-5341-4-2 
28. Kaese S, Frommeyer G, Verheule S, Van Loon G, Gehrmann J, Breithardt G, et al. The ECG in cardiovascular-relevant animal models of electrophysiology. Herzschrittmacherther Elektrophysiol. (2013) 24:84-91. doi: 10.1007/s00399-013-0260-Z

29. Chan YH, Tsai WC, Ko JS, Yin D, Chang PC, Rubart M, et al. Small-conductance calcium-activated potassium current is activated during hypokalemia and masks short-term cardiac memory induced by ventricular pacing. Circulation. (2015) 132:1377-86. doi: 10.1161/CIRCULATIONAHA.114.015125

30. Scamps F, Carmeliet E. Effect of external $\mathrm{K}+$ on the delayed $\mathrm{K}+$ current in single rabbit Purkinje cells. Pflügers Archiv. (1989) 414:S169-70. doi: 10.1007/BF00582287

31. Sanguinetti MC, Jurkiewicz NK. Role of external $\mathrm{Ca} 2+$ and $\mathrm{K}+$ in gating of cardiac delayed rectifier K+ currents. Pflügers Arch. (1992) 420:180-6. doi: 10.1007/BF00374988

32. Yang T, Snyders DJ, Roden DM. Rapid inactivation determines the rectification and $[\mathrm{K}+]_{0}$ dependence of the rapid component of the delayed rectifier K+ current in cardiac cells. Circ Res. (1997) 80:782-9. doi: 10.1161/01.RES.80.6.782

33. Bouchard R, Clark RB, Juhasz AE, Giles WR. Changes in extracellular K+ concentration modulate contractility of rat and rabbit cardiac myocytes via the inward rectifier K+ current IK1. J Physiol. (2004) 556:773-90. doi: 10.1113/jphysiol.2003.058248

34. Killeen MJ, Gurung IS, Thomas G, Stokoe KS, Grace AA, Huang CL. Separation of early afterdepolarizations from arrhythmogenic substrate in the isolated perfused hypokalaemic murine heart through modifiers of calcium homeostasis. Acta Physiol. (2007) 191:43-58. doi: 10.1111/j.1748-1716.2007.01715.x

35. El-Sherif N, Turitto G, Boutjdir M. Congenital long QT syndrome and torsade de pointes. Ann Noninvasive Electrocardiol. (2017) 22:e12481. doi: 10.1111 /anec. 12481

36. Guo J, Massaeli H, Xu J, Jia Z, Wigle JT, Mesaeli N, et al. Extracellular K+ concentration controls cell surface density of $\mathrm{IKr}$ in rabbit hearts and of the HERG channel in human cell lines. J Clin Invest. (2009) 119:2745-57. doi: 10.1172/JCI39027

37. Aronsen JM, Skogestad J, Lewalle A, Louch WE, Hougen K, Stokke MK, et al. Hypokalaemia induces $\mathrm{Ca}(2)(+)$ overload and $\mathrm{Ca}(2)(+)$ waves in ventricular myocytes by reducing $\mathrm{Na}(+), \mathrm{K}(+)$-ATPase alpha(2) activity. $J$ Physiol. (2015) 593:1509-21. doi: 10.1113/jphysiol.2014.279893

38. Pezhouman A, Singh N, Song Z, Nivala M, Eskandari A, Cao H, et al. Molecular basis of hypokalemia-induced ventricular fibrillation. Circulation. (2015) 132:1528-37. doi: 10.1161/CIRCULATIONAHA.115.016217

39. Hondeghem LM, Carlsson L, Duker G. Instability and triangulation of the action potential predict serious proarrhythmia, but action potential duration prolongation is antiarrhythmic. Circulation. (2001) 103:2004-13. doi: 10.1161/01.CIR.103.15.2004

40. Shapiro JI, Banerjee A, Reiss OK, Elkins N. Acute and chronic hypokalemia sensitize the isolated heart to hypoxic injury. Am J Physiol. (1998) 274:H1598-1604. doi: 10.1152/ajpheart.1998.274.5.H1598

41. Tribulova N, Manoach M, Varon D, Okruhlicova L, Zinman T, Shainberg A. Dispersion of cell-to-cell uncoupling precedes low $\mathrm{K}+$-induced ventricular fibrillation. Physiol Res. (2001) 50:247-59.

42. January CT, Riddle JM, Salata JJ. A model for early afterdepolarizations: induction with the Ca2+ channel agonist Bay K 8644. Circ Res. (1988) 62:563-71. doi: 10.1161/01.RES.62.3.563

43. Killeen MJ, Thomas G, Gurung IS, Goddard CA, Fraser JA, MahautSmith MP, et al. Arrhythmogenic mechanisms in the isolated perfused hypokalaemic murine heart. Acta Physiol. (2007) 189:33-46. doi: 10.1111/j.1748-1716.2006.01643.x

44. Maruyama M, Ai T, Chua SK, Park HW, Lee YS, Shen MJ, et al. Hypokalemia promotes late phase 3 early afterdepolarization and recurrent ventricular fibrillation during isoproterenol infusion in Langendorff perfused rabbit ventricles. Heart Rhythm. (2014) 11:697-706. doi: 10.1016/j.hrthm.2013.12.032

45. Chang PC, Lu YY, Lee HL, Lin SF, Chu Y, Wen MS, et al. Paradoxical effects of sodium-calcium exchanger inhibition on torsade de pointes and early afterdepolarization in a heart failure rabbit model. J Cardiovasc Pharmacol. (2018) 72:97-105. doi: 10.1097/FJC.0000000000000598
46. Gilat E, Nordin CW, Aronson RS. The role of reduced potassium conductance in generating triggered activity in guineapig ventricular muscle. J Mol Cell Cardiol. (1990) 22:619-28. doi: 10.1016/0022-2828(90)90963-3

47. Ohta M, Karagueuzian HS, Mandel WJ, Peter T. Acute and chronic effects of amiodarone on delayed afterdepolarization and triggered automaticity in rabbit ventricular myocardium. Am Heart J. (1987) 113:289-96. doi: 10.1016/0002-8703(87)90267-5

48. Bellet S, Nadler CS, Gazes PC. Effect of vomiting due to intestinal obstruction on the serum potassium; chemical and electrocardiographic observations in 15 cases; preliminary report. Am J Med. (1949) 6:712-24. doi: 10.1016/0002-9343(49)90307-1

49. Surawicz B, Lepeschkin E. The electrocardiographic pattern of hypopotassemia with and without hypocalcemia. Circulation. (1953) 8:801-28. doi: 10.1161/01.CIR.8.6.801

50. Singer DH, Lazzara R, Hoffman BF. Interrelationship between automaticity and conduction in Purkinje fibers. Circ Res. (1967) 21:537-58. doi: 10.1161/01.RES.21.4.537

51. Liu MB, De Lange E, Garfinkel A, Weiss JN, Qu Z. Delayed afterdepolarizations generate both triggers and a vulnerable substrate promoting reentry in cardiac tissue. Heart Rhythm. (2015) 12:2115-24. doi: 10.1016/j.hrthm.2015.06.019

52. Tse G, Wong ST, Tse V, Lee YT, Lin HY, Yeo JM. Cardiac dynamics: alternans and arrhythmogenesis. J Arrhythm. (2016) 32:411-7. doi: 10.1016/j.joa.2016.02.009

53. Poelzing S, Veeraraghavan R. Heterogeneous ventricular chamber response to hypokalemia and inward rectifier potassium channel blockade underlies bifurcated T wave in guinea pig. Am J Physiol Heart Circ Physiol. (2007) 292:H3043-51. doi: 10.1152/ajpheart.01312.2006

54. Tse G. Mechanisms of cardiac arrhythmias. J Arrhythm. (2015) 32:75-81. doi: 10.1016/j.joa.2015.11.003

55. Warren M, Guha PK, Berenfeld O, Zaitsev A, Anumonwo JM, Dhamoon AS, et al. Blockade of the inward rectifying potassium current terminates ventricular fibrillation in the guinea pig heart. J Cardiovasc Electrophysiol. (2003) 14:621-31. doi: 10.1046/j.1540-8167.2003.03006.x

56. Veeraraghavan R, Poelzing S. Mechanisms underlying increased right ventricular conduction sensitivity to flecainide challenge. Cardiovasc Res. (2008) 77:749-56. doi: 10.1093/cvr/cvm090

57. Nikolic G, Bishop RL, Singh JB. Sudden death recorded during Holter monitoring. Circulation. (1982) 66:218-25. doi: 10.1161/01.CIR.66.1.218

58. Olshausen KV, Witt T, Pop T, Treese N, Bethge KP, Meyer J. Sudden cardiac death while wearing a Holter monitor. Am J Cardiol. (1991) 67:381-6. doi: 10.1016/0002-9149(91)90046-N

59. Sabir IN, Fraser JA, Killeen MJ, Grace AA, Huang CL. The contribution of refractoriness to arrhythmic substrate in hypokalaemic Langendorff-perfused murine hearts. Pflugers Arch. (2007) 454:209-22. doi: 10.1007/s00424-007-0217-3

60. Sabir IN, Killeen MJ, Goddard CA, Thomas G, Gray S, Grace AA, et al. Transient alterations in transmural repolarization gradients and arrhythmogenicity in hypokalaemic Langendorff-perfused murine hearts. $J$ Physiol. (2007) 581:277-89. doi: 10.1113/jphysiol.2007.128637

61. Nolasco JB, Dahlen RW. A graphic method for the study of alternation in cardiac action potentials. J Appl Physiol. (1968) 25:191-6. doi: 10.1152/jappl.1968.25.2.191

62. Hondeghem LM, Snyders DJ. Class III antiarrhythmic agents have a lot of potential but a long way to go. Reduced effectiveness and dangers of reverse use dependence. Circulation. (1990) 81:686-90. doi: 10.1161/01.CIR. 81.2.686

63. Sabir IN, Li LM, Grace AA, Huang CL. Restitution analysis of alternans and its relationship to arrhythmogenicity in hypokalaemic Langendorff-perfused murine hearts. Pflugers Arch. (2008) 455:653-66. doi: 10.1007/s00424-007-0327-y

64. Cherry EM, Fenton FH. Suppression of alternans and conduction blocks despite steep APD restitution: electrotonic, memory, and conduction velocity restitution effects. Am J PhysiolHeart Circ Physiol. (2004) 286:H2332-41. doi: 10.1152/ajpheart.00747.2003

65. Wu R, Patwardhan A. Mechanism of repolarization alternans has restitution of action potential duration dependent and 
independent components. J Cardiovasc Electrophysiol. (2006) 17:87-93. doi: 10.1111/j.1540-8167.2005.00319.x

66. Zaniboni M, Riva I, Cacciani F, Groppi M. How different two almost identical action potentials can be: a model study on cardiac repolarization. Math Biosci. (2010) 228:56-70. doi: 10.1016/j.mbs.2010.08.007

67. Zaniboni M. 3D current-voltage-time surfaces unveil critical repolarization differences underlying similar cardiac action potentials: a model study. Math Biosci. (2011) 233:98-110. doi: 10.1016/j.mbs.2011.06.008

68. Zaniboni M. Late phase of repolarization is autoregenerative and scales linearly with action potential duration in mammals ventricular myocytes: a model study. IEEE Trans Biomed Eng. (2012) 59:226-33. doi: 10.1109/TBME.2011.2170987

69. Zaniboni M. Short-term action potential memory and electrical restitution: a cellular computational study on the stability of cardiac repolarization under dynamic pacing. PLoS ONE. (2018) 13:e0193416. doi: 10.1371/journal.pone.0193416

70. Zaniboni M. Restitution and stability of human ventricular action potential at high and variable pacing rate. Biophys J. (2019) 117:2382-95. doi: 10.1016/j.bpj.2019.08.020

71. Zaniboni M, Cacciani F. Restitution and adaptation measurements for the estimate of short-term cardiac action potential memory: comparison of five human ventricular models. Europace. (2019) 21:1594-602. doi: 10.1093/europace/euz205

72. Yue AM. Letter regarding article by Koller et al. Altered dynamics of action potential restitution and alternans in humans with structural heart disease. Circulation. (2006) 113:e462; author reply e462. doi: 10.1161/CIRCULATIONAHA.105.597310

73. Tse G, Liu T, Li G, Keung W, Yeo JM, Fiona Chan YW, et al. Effects of pharmacological gap junction and sodium channel blockade on S1S2 restitution properties in Langendorff-perfused mouse hearts. Oncotarget. (2017) 8:85341-52. doi: 10.18632/oncotarget.19675

74. Holmberg S, Varnauskas E. Coronary circulation during pacinginduced tachycardia. Acta Med Scand. (1971) 190:481-90. doi: 10.1111/j.0954-6820.1971.tb07463.x

75. Graber JD, Conti CR, Lappe DL, Ross RS. Effect of pacinginduced tachycardia and myocardial ischemia on ventricular pressure-velocity relationships in man. Circulation. (1972) 46:74-83. doi: 10.1161/01.CIR.46.1.74

76. Vaidya D, Morley GE, Samie FH, Jalife J. Reentry and fibrillation in the mouse heart. A challenge to the critical mass hypothesis. Circ Res. (1999) 85:174-81. doi: 10.1161/01.RES.85.2.174

77. Uchida T, Yashima M, Gotoh M, Qu Z, Garfinkel A, Weiss JN, et al. Mechanism of acceleration of functional reentry in the ventricle. Effects of ATP-Sensitive Potassium Channel Opener. (1999) 99:704-12. doi: 10.1161/01.CIR.99.5.704

78. Tse G, Yeo JM. Conduction abnormalities and ventricular arrhythmogenesis: the roles of sodium channels and gap junctions. Int J Cardiol Heart Vasc. (2015) 9:75-82. doi: 10.1016/j.ijcha.2015.10.003

79. Lammers WJ, Allessie MA, Bonke FI. Reentrant and focal arrhythmias in low potassium in isolated rabbit atrium. Am J Physiol. (1988) 255:H1359-1369. doi: 10.1152/ajpheart.1988.255.6.H1359

80. Kishida H, Surawicz B, Fu LT. Effects of $\mathrm{K}+$ and $\mathrm{K}+$-induced polarization on $(\mathrm{dV} / \mathrm{dt}) \max$, threshold potential, and membrane input resistance in guinea pig and cat ventricular myocardium. Circ Res. (1979) 44:800-14. doi: 10.1161/01.RES.44.6.800

81. Ruiz-Ceretti E, Ponce-Zumino A, Blaney R, Chartier D. Experimental arrhythmia elicited by low K perfusion. Can J Physiol Pharmacol. (1982) 60:1533-40. doi: 10.1139/y82-226

82. Laurita KR, Girouard SD, Rudy Y, Rosenbaum DS. Role of passive electrical properties during action potential restitution in intact heart. Am J Physiol. (1997) 273:H1205-1214. doi: 10.1152/ajpheart.1997.273.3.H1205

83. Prothero J. Heart weight as a function of body weight in mammals. Growth. (1979) 43:139-50.

84. Nerbonne JM. Studying cardiac arrhythmias in the mouse-a reasonable model for probing mechanisms? Trends Cardiovasc Med. (2004) 14:83-93. doi: $10.1016 /$ j.tcm.2003.12.006

85. Yeo JM, Tse V, Kung J, Lin HY, Lee YT, Kwan J, et al. Isolated heart models for studying cardiac electrophysiology: a historical perspective and recent advances. J Basic Clin Physiol Pharmacol. (2017) 28:191-200. doi: 10.1515/jbcpp-2016-0110

86. Tse G, Du Y, Hao G, Li KHC, Chan FYW, Liu T, et al. Quantification of beat-to-beat variability of action potential durations in langendorff-perfused mouse hearts. Front Physiol. (2018) 9:1578. doi: 10.3389/fphys.2018.01578

87. Zicha S, Moss I, Allen B, Varro A, Papp J, Dumaine R, et al. Molecular basis of species-specific expression of repolarizing $\mathrm{K}+$ currents in the heart. Am J Physiol Heart Circ Physiol. (2003) 285:H1641-1649. doi: 10.1152/ajpheart.00346.2003

88. Szentadrassy N, Banyasz T, Biro T, Szabo G, Toth BI, Magyar J, et al. Apico-basal inhomogeneity in distribution of ion channels in canine and human ventricular myocardium. Cardiovasc Res. (2005) 65:851-60. doi: $10.1016 /$ j.cardiores.2004.11.022

89. Allison JS, Qin H, Dosdall DJ, Huang J, Newton JC, Allred JD, et al. The transmural activation sequence in porcine and canine left ventricle is markedly different during long-duration ventricular fibrillation. J Cardiovasc Electrophysiol. (2007) 18:1306-12. doi: 10.1111/j.1540-8167.2007.00963.x

90. Fedorov VV, Glukhov AV, Chang R. Conduction barriers and pathways of the sinoatrial pacemaker complex: their role in normal rhythm and atrial arrhythmias. Am J Physiol Heart Circ Physiol. (2012) 302:H1773-1783. doi: 10.1152/ajpheart.00892.2011

91. Decloedt A, Schwarzwald CC, De Clercq D, Van Der Vekens N, Pardon $\mathrm{B}$, Reef VB, et al. Risk factors for recurrence of atrial fibrillation in horses after cardioversion to sinus rhythm. J Vet Intern Med. (2015) 29:946-53. doi: $10.1111 /$ jvim. 12606

92. Linz D, Van Hunnik A, Hohl M, Mahfoud F, Wolf M, Neuberger HR, et al. Catheter-based renal denervation reduces atrial nerve sprouting and complexity of atrial fibrillation in goats. Circ Arrhythm Electrophysiol. (2015) 8:466-74. doi: 10.1161/CIRCEP.114.002453

93. Dominguez G, Fozzard HA. Influence of extracellular $\mathrm{K}+$ concentration on cable properties and excitability of sheep cardiac Purkinje fibers. Circ Res. (1970) 26:565-74. doi: 10.1161/01.RES.26.5.565

94. Chah QT, Braly G, Bouzouita K, Faucon G. Effects of hypokalemia on the various parts of the conduction system of the dog heart in situ. Naunyn Schmiedebergs Arch Pharmacol. (1982) 319:178-83. doi: 10.1007/BF00503934

95. Litovsky SH, Antzelevitch C. Rate dependence of action potential duration and refractoriness in canine ventricular endocardium differs from that of epicardium: role of the transient outward current. J Am Coll Cardiol. (1989) 14:1053-66. doi: 10.1016/0735-1097(89)90490-7

96. Di Diego JM, Sun ZQ, Antzelevitch C. I(to) and action potential notch are smaller in left vs. right canine ventricular epicardium. Am J Physiol. (1996) 271:H548-561. doi: 10.1152/ajpheart.1996.271.2.H548

97. Volders PG, Sipido KR, Carmeliet E, Spatjens RL, Wellens HJ, Vos MA. Repolarizing $\mathrm{K}+$ currents ITO1 and IKs are larger in right than left canine ventricular midmyocardium. Circulation. (1999) 99:206-10. doi: 10.1161/01.CIR.99.2.206

98. Tazmini K, Frisk M, Lewalle A, Laasmaa M, Morotti S, Lipsett DB, et al. Hypokalemia promotes arrhythmia by distinct mechanisms in atrial and ventricular myocytes. Circ Res. (2020) 126:889-906. doi: 10.1161/CIRCRESAHA.119.315641

99. Diness JG, Abildgaard L, Bomholtz SH, Skarsfeldt MA, Edvardsson N, Sorensen US, et al. Inhibition of $\mathrm{KCa} 2$ channels decreased the risk of ventricular arrhythmia in the guinea pig heart during induced hypokalemia. Front Pharmacol. (2020) 11:749. doi: 10.3389/fphar.2020.00749

100. Bentzen BH, Bomholtz SH, Simó-Vicens R, Folkersen L, Abildgaard $\mathrm{L}$, Speerschneider T, et al. Mechanisms of action of the KCa2negative modulator AP30663, a novel compound in development for treatment of atrial fibrillation in man. Front Pharmacol. (2020) 11:610. doi: 10.3389/fphar.2020.00610

101. Bertrix L, Bouzouita K, Lang J, Lakhal M, Chah QT, Faucon G. Potentiation by hypokalemia of the effects of acetylcholine on the canine heart in situ. Naunyn Schmiedebergs Arch Pharmacol. (1984) 326:169-74. doi: 10.1007/BF00517315

102. Veress G. Hypokalemia associated with infra-his mobitz type second degree A-V block. Chest. (1994) 105:1616-7. doi: 10.1378/chest.105.5.1616

103. Jost N, Virag L, Comtois P, Ordog B, Szuts V, Seprenyi G, et al. Ionic mechanisms limiting cardiac repolarization reserve in humans compared 
to dogs. J Physiol. (2013) 591:4189-206. doi: 10.1113/jphysiol.2013. 261198

104. Lemoine MD, Krause T, Koivumaki JT, Prondzynski M, Schulze ML, Girdauskas E, et al. Human induced pluripotent stem cell-derived engineered heart tissue as a sensitive test system for QT prolongation and arrhythmic triggers. Circ Arrhythm Electrophysiol. (2018) 11:e006035. doi: 10.1161/CIRCEP.117.006035

105. Nash MP, Bradley CP, Sutton PM, Clayton RH, Kallis P, Hayward MP, et al. Whole heart action potential duration restitution properties in cardiac patients: a combined clinical and modelling study. Exp Physiol. (2006) 91:339-54. doi: 10.1113/expphysiol.2005.031070

106. Nicolson WB, Mccann GP, Brown PD, Sandilands AJ, Stafford PJ, Schlindwein FS, et al. A novel surface electrocardiogram-based marker of ventricular arrhythmia risk in patients with ischemic cardiomyopathy. J Am Heart Assoc. (2012) 1:e001552. doi: 10.1161/xJAHA.111.001552

107. Nicolson WB, Mccann GP, Smith MI, Sandilands AJ, Stafford PJ, Schlindwein FS, et al. Prospective evaluation of two novel ECGbased restitution biomarkers for prediction of sudden cardiac death risk in ischaemic cardiomyopathy. Heart. (2014) 100:1878-85. doi: 10.1136/heartjnl-2014-305672

108. Farah R, Nassar M, Aboraya B, Nseir W. Low serum potassium levels are associated with the risk of atrial fibrillation. Acta Cardiol. (2020) 1-4. doi: 10.1080/00015385.2020.1799573

109. Laslett DB, Cooper JM, Greenberg RM, Yesenosky GA, Basil A, Gangireddy $\mathrm{C}$, et al. Electrolyte abnormalities in patients presenting with ventricular arrhythmia (from the LYTE-VT Study). Am J Cardiol. (2020) 129:36-41. doi: 10.1016/j.amjcard.2020.04.051

110. Danielsson B, Collin J, Nyman A, Bergendal A, Borg N, State M, et al. Drug use and torsades de pointes cardiac arrhythmias in Sweden: a nationwide register-based cohort study. BMJ Open. (2020) 10:e034560. doi: 10.1136/bmjopen-2019-034560

111. Muhammad Ali S, Shaikh N, Shahid F, Shah A, Zafar HB. Hypokalemia leading to postoperative critical arrhythmias: case reports and literature review. Cureus. (2020) 12:e8149. doi: 10.7759/cureus.8149

112. Schupp T, Behnes M, Zworowsky MV, Kim SH, Weidner K, Rusnak J, et al. Hypokalemia but not hyperkalemia is associated with recurrences of ventricular tachyarrhythmias in ICD recipients. Clin Lab. (2020) 66:457-65. doi: 10.7754/Clin.Lab.2019.190645

113. Valentova M, Patel S, Lam PH, Faselis C, Arundel C, Fonarow GC, et al. Hypokalaemia and outcomes in older patients hospitalized for heart failure. ESC Heart Fail. (2020) 7:794-803. doi: 10.1002/ehf2.12666

114. Harkness W, Watts P, Kopstein M, Dziadkowiec O, Hicks G, Scherbak D. Correcting hypokalemia in hospitalized patients does not decrease risk of cardiac arrhythmias. Adv Med. (2019) 2019:4919707. doi: 10.1155/2019/4919707

115. Tse G, Gong M, Meng L, Wong CW, Bazoukis G, Chan MTV, et al. Predictive value of tpeak - tend indices for adverse outcomes in acquired qt prolongation: a meta-analysis. Front Physiol. (2018) 9:1226. doi: 10.3389/fphys.2018.01226

116. Chen C, Zhou J, Yu H, Zhang Q, Gao L, Yin X, et al. Identification of important risk factors for all-cause mortality of acquired long QT syndrome patients using random survival forests and nonnegative matrix factorization. Heart Rhythm. (2020) (In press). doi: 10.1016/j.hrthm.2020.10.022

117. Skogestad J, Aronsen JM. Hypokalemia-Induced Arrhythmias and Heart Failure: New Insights and Implications for Therapy. Front Physiol. (2018) 9:1500. doi: 10.3389/fphys.2018.01500

118. Singh SN, Carson PE, Fisher SG. Nonsustained ventricular tachycardia in severe heart failure. Circulation. (1997) 96:3794-5.

119. Teerlink JR, Jalaluddin M, Anderson S, Kukin ML, Eichhorn EJ, Francis G, et al. Ambulatory ventricular arrhythmias in patients with heart failure do not specifically predict an increased risk of sudden death. PROMISE (prospective randomized milrinone survival evaluation) investigators. Circulation. (2000) 101:40-6. doi: 10.1161/01.CIR.101.1.40
120. Tomaselli GF, Zipes DP. What causes sudden death in heart failure? Circ Res. (2004) 95:754-63. doi: 10.1161/01.RES.0000145047.14691.db

121. Ebinger MW, Krishnan S, Schuger CD. Mechanisms of ventricular arrhythmias in heart failure. Curr Heart Fail Rep. (2005) 2:111-7.

122. Jin $\mathrm{H}$, Lyon AR, Akar FG. Arrhythmia mechanisms in the failing heart. Pacing Clin. Electrophysiol. (2008) 31:1048-56. doi: $10.1111 / j .1540-8159.2008 .01134 . x$

123. Colombo MG, Kirchberger I, Amann U, Dinser L, Meisinger C. Association of serum potassium concentration with mortality and ventricular arrhythmias in patients with acute myocardial infarction: a systematic review and meta-analysis. Eur J Prev Cardiol. (2018) 25:576-95. doi: $10.1177 / 2047487318759694$

124. Motloch LJ, Ishikawa K, Xie C, Hu J, Aguero J, Fish KM, et al. Increased afterload following myocardial infarction promotes conduction-dependent arrhythmias that are unmasked by hypokalemia. JACC Basic Transl Sci. (2017) 2:258-69. doi: 10.1016/j.jacbts.2017.02.002

125. Gennari FJ. Hypokalemia. N Engl J Med. (1998) 339:451-8. doi: 10.1056/NEJM199808133390707

126. Krogager ML, Eggers-Kaas L, Aasbjerg K, Mortensen RN, Kober L, Gislason $\mathrm{G}$, et al. Short-term mortality risk of serum potassium levels in acute heart failure following myocardial infarction. Eur Heart J Cardiovasc Pharmacother. (2015) 1:245-51. doi: 10.1093/ehjcvp/pvv026

127. Su J, Fu X, Tian Y, Ma Y, Chen H, Wang Y, et al. Additional predictive value of serum potassium to thrombolysis in myocardial infarction risk score for early malignant ventricular arrhythmias in patients with acute myocardial infarction. Am J Emerg Med. (2012) 30:1089-94. doi: 10.1016/j.ajem.2011.07.009

128. Colombo MG, Kirchberger I, Amann U, Heier M, Thilo C, Kuch B, et al. Admission serum potassium concentration and long-term mortality in patients with acute myocardial infarction: results from the MONICA/KORA myocardial infarction registry. BMC Cardiovasc Disord. (2017) 17:198. doi: 10.1186/s12872-017-0635-x

129. Ravn Jacobsen M, Jabbari R, Glinge C, Kjaer Stampe N, Butt JH, Blanche $\mathrm{P}$, et al. Potassium disturbances and risk of ventricular fibrillation among patients with ST-segment-elevation myocardial infarction. J Am Heart Assoc. (2020) 9:e014160. doi: 10.1161/JAHA.119.014160

130. Darbar D, Sile S, Fish FA, George AL Jr. Congenital long QT syndrome aggravated by salt-wasting nephropathy. Heart Rhythm. (2005) 2:304-6. doi: 10.1016/j.hrthm.2004.11.015

131. Berthet M, Denjoy I, Donger C, Demay L, Hammoude H, Klug D, et al. Cterminal HERG mutations: the role of hypokalemia and a KCNQ1-associated mutation in cardiac event occurrence. Circulation. (1999) 99:1464-70. doi: 10.1161/01.CIR.99.11.1464

132. Kubota T, Shimizu W, Kamakura S, Horie M. Hypokalemia-induced long QT syndrome with an underlying novel missense mutation in S4S5 linker of KCNQ1. J Cardiovasc Electrophysiol. (2000) 11:1048-54. doi: 10.1111/j.1540-8167.2000.tb00178.x

133. Christiansen M, Kjeldsen K, Wettrell G, Larsen LA, Lundkvist L, Andersen PS, et al. potassium must be considered in congenital long QT syndrome. Heart Drug. (2005) 5:54-8. doi: 10.1159/000083388

134. Kääb S. Potassium in Long QT Syndromes. Heart Drug. (2005) 5:51-3. doi: $10.1159 / 000083387$

Conflict of Interest: The authors declare that the research was conducted in the absence of any commercial or financial relationships that could be construed as a potential conflict of interest.

Copyright (๑) 2021 Tse, Li, Cheung, Letsas, Bhardwaj, Sawant, Liu, Yan, Zhang, Jeevaratnam, Sayed, Cheng and Wong. This is an open-access article distributed under the terms of the Creative Commons Attribution License (CC BY). The use, distribution or reproduction in other forums is permitted, provided the original author(s) and the copyright owner(s) are credited and that the original publication in this journal is cited, in accordance with accepted academic practice. No use, distribution or reproduction is permitted which does not comply with these terms. 